\title{
La construcción social de los cuerpos o los cuerpos del capitalismo tardío
}

Liuba Kogan

Universidad de Lima

El texto propone considerar a los cuerpos vigoréxicos, anoréxicos o bulímicos como cuerpos liminales: son los extremos de una escala donde el eje central es el ideal corporal de esbeltez de las sociedades del capitalismo tardio. Se parte de la premisa de que los cuerpos son productores y transmisores de significados sociales y que las prácticas alimenticias siempre han estado cargadas de sentido como procesos sociales (sostén, placer, ritual, intercambio, incorporación de lo exterior al interior corporal). Sin embargo, se analizan las características sociohistóricas que permiten entender las relaciones que establecen las personas con la alimentación y la construcción de la corporalidad en sociedades tradicionales, modernas y de la modernidad tardía.

anorexia / bulimia / trastornos alimenticios

\section{The social construction of the bodies or the bodies of late capitalism}

The text proposes to consider that invigorated, anorexic or bulimic bodies are borderline bodies: are the extremes of a scale where the central axle is the corporal ideal of slenderness in societies of the late capitalism. We start form the premise that bodies are social meaning producers and transmitters and that nutritional practices have always loaded with sense as social processes (support, pleasure, ritual, interchange, incorporation of the outside into the corporal interior). Nevertheless, socio-historical characteristics are analyzed allowing the understanding of relationships established by people with food and construction of the embodiment in traditional and modern societies, and late modernity.

anorexia / bulimia / nutritional desorders

Correo electrónico: lkogan@correo.ulima.edu.pe 
Los cuerpos han sido y son, desde los albores de la humanidad, receptores de significados sociales como también productores y transmisores de significados. Los cuerpos han jugado siempre una función simbólica. Podemos señalarlo de otra manera: los cuerpos son producto de una construcción social: están insertos en una época y en una sociedad particulares. Pero además las personas tienen la capacidad de expresar significados con sus cuerpos. ¿Qué significa eso? Que toda sociedad implanta políticas o pedagogías para la gestión o manipulación de los cuerpos pero a la vez éstos pueden convertirse en locus de resistencia o de expresión simbólica.

Quiero graficar con dos ejemplos las políticas que las sociedades instauran en nuestra corporalidad:

- En Estados Unidos encontramos una valoración considerable del cuerpo juvenil. La publicidad, como las estrellas de TV, nos lo demuestra. Así, un cuerpo que envejece -un cuerpo menopáusico- es representado como un cuerpo en declive, casi un desecho humano. Ello explica que el cuerpo de la mujer madura se haya convertido en ese país en una categoría epidemiológica de riesgo, recomendándose terapias de reemplazo hormonal a diestra y siniestra. Sin embargo, sucede que en el Japón, la mujer madura no es vista como portadora de un cuerpo en declive, ya que luego de cul- minar su etapa reproductiva, aparece una nueva función social para ella: cuidadora de los adultos mayores en el hogar. Ello lleva a que pocas mujeres en el Japón reconozcan los síntomas de la menopausia que sufren las norteamericanas, ya que desde su perspectiva cultural "solo las mujeres egoístas sufren problemas de menopausia". Desde este punto de vista, pues, las mujeres tienen una función social valorada que cumplir, a pesar del envejecimiento. Dicho sea de paso, es la etapa del ciclo de la vida que se valora y reverencia, a diferencia de la sociedad norteamericana donde lo no juvenil se halla devaluado (Lock, 1993).

- En Corea la mujer tradicionalmente fue considerada la alimentadora de la familia, su función social es altamente valorada y su vida está orientada a cuidar y mostrar afecto a partir de los rituales de la alimentación. Sin embargo, con la introducción de la publicidad occidental con modelos anoréxicas, las jóvenes empezaron a hacer dietas y a odiar "sus rostros y cuerpos redondeados" y las madres empezaron a sentirse desubicadas respecto de su identidad social. Las imágenes del cuerpo ideal de la mujer cambiaron significativamente, de las antiguas imágenes regordetas que simbolizaban abundancia y productividad hacia las nuevas imágenes de mujeres esbeltas (Dongju, 1998). 
Podemos ver, pues, que a través de diferentes esferas públicas se van a construir las imágenes corporales deseables o ideales y se van a recomendar formas para trabajar esos cuerpos.

También es cierto que los cuerpos pueden constituirse en locus o espacios de performance cultural de resistencia: las sociedades tradicionales conocen ritos de exorcismo, cultos de posesión y todo un repertorio de expresiones corporales de "nervios" de aquellas categorías de personas que carecen de poder y somatizan estados devaluados de vida.

Si bien el cuerpo es y ha sido una dimensión fundamental en las sociedades desde los albores de la humanidad, resulta muy significativo que para los científicos sociales el cuerpo haya sido una categoría elusiva, incluso más que la función del comer (Turner, 1996). Los estudios sobre el cuerpo han sido -hasta hace pocos años en la sociología- bastante marginales. Sin embargo, los antropólogos han indagado acerca de las funciones sociales del comer: sostén, placer, ritual, intercambio con los otros, incorporación de elementos externos en el interior, etc. (ScheperHuges, 1997). Incluso nos muestran que han existido ideales diversos en torno a la corporalidad: desde la valoración del no comer o abstinencia y la producción de cuerpos desnutridos; al comer en exceso y la producción de cuerpos obesos. En unos u otros casos, es de notar que dichas sociedades no han considerado esos estados bajo la etiqueta occidental y contemporánea de "desórdenes alimenticios". Algunos estudios muestran (Messer, 1984) que en sociedades donde se valora la sobrealimentación y la obesidad, parece existir un miedo residual a las hambrunas o, de lo contrario, la muestra del afecto y el cuidado se encuentran asociados a la función alimentadora. Por otra parte, algunos otros estudios empíricos en sociedades tradicionales parecen mostrar que en sociedades tradicionales donde se valora la esbeltez, y la abstinencia o ayuno son vistos como virtudes-, tiende a tratarse de sociedades donde la dotación de alimentos es irregular. No pretendemos proponer un determinismo material, pero nos interesa resaltar los diversos factores que pueden llevar a la generación de ideologías tan diversas sobre la alimentación y la producción de cuerpos. Quiero puntualizar que, en el fondo, estamos ante un viejo problema: la alimentación y la producción de los cuerpos; pero en un entorno hoy radicalmente diferente. ¿Por qué?

Pasemos a hacer un breve recorrido histórico:

En sociedades tradicionales los cuerpos encarnan la estructura social: cada casta, clan, grupo étnico, sector social, etc., tenía un particular modo de gestionar su corporalidad. Ciertas ropas, colores, tipos de tocados, eran exclusivos para determinados grupos sociales. La gestión corporal estaba ads- 
crita a la posición social desde el nacimiento. Podemos señalar, pues, la vigencia de una metafísica de la profundidad: lo que parece es y viceversa. No es posible separar el parecer del ser, a menos que el sujeto se disfrace; es decir, engañe (use un adorno corporal que no le pertenezca). Así, en este tipo de sociedades, los cuerpos no sólo tienen una apariencia que corresponde a la categoría social de nacimiento, sino además los modelos de gestión corporal se mantienen en el tiempo generacionalmente. Paralelo a la inmovilidad o rigidez en la construcción de la corporalidad en este tipo de sociedades, es imprescindible señalar que el sujeto no se representa como individuo: no existe una conciencia clara del propio rostro, de la forma del cuerpo, de las huellas del tiempo en la corporalidad. La personalidad no se ancla en la corporalidad individualizada sino en la colectividad: hijo de quién eres, a qué clan perteneces, cuál es tu grupo étnico, etc.

Sin embargo, con el advenimiento de la Ilustración, del capitalismo y de la modernidad, se va a producir una revolución en la gestión de la corporalidad. Por una parte, se va a generar la individualización de los sujetos: conciencia del propio rostro y cuerpo. Aparecen los carnés de identidad, el registro de huellas digitales, las fotografias, los diarios personales, las camas individuales, los espejos de cuerpo entero (que por primera vez se colocan en los burdeles y luego en el interior de las puer- tas de los roperos) porque mirar el propio cuerpo era signo de lo abyecto y de pecado (Duby y Perrot, 1993). Es decir, el sujeto se identificará con un cuerpo que considera único. Y de otro lado, se va a democratizar el adorno corporal: cualquiera puede usar el tipo de adorno corporal que desee. Ya no encontramos restricciones debidas a la categoría social de nacimiento. La persona puede cambiar de ropas o adornos según las épocas del año, los momentos del día, las estaciones o según las actividades que se realicen. Es en este momento histórico en el que aparece por primera vez el concepto de moda: el imperio de lo efímero (Lipovetsky, 1990). Los medios de comunicación empezarán a mostrar modelos de adorno corporal, que serán adoptados y desechados permanentemente por los diversos grupos sociales. La moda, será funcional al capitalismo, pues llevará a que se construyan permanentemente nuevas necesidades en torno a la corporalidad y ello generará una demanda constante sobre productos para gestionar el cuerpo. Y así las fábricas permanentemente producirán nuevos bienes y servicios para el mercado. Como todos los individuos pueden vestir de modo similar, aparecerán dos maneras de generar la distinción social: las marcas generarán una manera de construir y representar las diferencias sociales porque sólo algunos podrán acceder a vestir o tener bienes de ciertas marcas. Pero, además, la distinción social en este entorno de abundan- 
cia de bienes, se construirá a partir de la abstinencia alimenticia y de la valoración de la esbeltez. Porque sólo los que tienen qué comer pueden darse el lujo de dejar de comer.

Me parece importante incidir aún más en la caracterización de las sociedades modernas para relacionar su eticidad con la generación de nuevos modelos de corporalidad. Según Charles Taylor (Taylor, 1994), las personas en las sociedades capitalistas sufriríamos tres formas de malestar:

- El individualismo, que nos lleva al egocentrismo y por lo tanto a una pérdida del sentido o a la dificultad de ubicar nuestra existencia en el marco de amplios horizontes sociales, históricos y políticos. El sujeto se siente solo, desencantado, ha perdido el ideal heroico de la vida que lo llevaba a mirar más allá de sí mismo para intentar reencontrarse con los otros: vive un lastimoso bienestar material. Por ello, concomitantemente, el egocentrismo nos lleva a centrarnos en el cuerpo, lo más próximo que tenemos y aquello que sí podemos controlar. El cuerpo se convierte en el escenario de los significados sociales que vive el individuo.

- La primacía de la razón instrumental; es decir, las personas ya no orientan su vida a partir de los postulados de la religión o de la tradición, sino más bien a partir de una lógica del costo-beneficio. En otras palabras, vivimos un desasosiego producto de nuestra necesidad de reconocimiento externo, ya que se han eclipsado los grandes fines o ideales que nos proponía la tradición o la religión. Por ello, tendemos a ver el cuerpo como artefacto $\mathrm{u}$ objeto que puede someterse a prácticas tecnológicas (como las liposucciones, los ayunos, vómitos, implantes, etc.) con la ilusión de restaurar un narcisismo perdido.

- La pérdida de libertad para ser espontáneos, para librarnos de la tiranía de la publicidad, de los cuerpos que nos enrostran las modelos anoréxicas, de la perfección, del exitismo y de una muy fuerte exigencia de autonomía personal.

Entonces, tal es la fuerza del egocentrismo que nos lleva a pensar en nosotros y en nuestro cuerpo; de la razón instrumental que nos lleva a objetivarlo y de la autoexigencia de perfección sobre la corporalidad, que en esta época del capitalismo tardío ya no sólo importa qué te pongas y de qué marca sea, sino que el mismo cuerpo desnudo debe poder mostrarse sin temor. El cuerpo parece haberse convertido en el proyecto de vida de muchas personas. "El salón parece una pasarela" comentaba una alumna de sector medio alto en relación al salón de clase en su universidad. Mientras un joven homosexual limeño de sector popular señalaba en una entrevista: 
Yo soy una personalidad y mi cuerpo es la expresión de mi personalidad ante los demás. A través de él puedo manifestar muchas cosas, los demás pueden enterarse de manifestaciones de mi carácter a través de mi cuerpo. O sea, en algunos momentos pensaba que era algo así, como que era un ser espiritual dentro de un cuerpo, pero poco a poco he ido aprendiendo que yo también soy este cuerpo (Asociación Germinal, 1996).

Así, todo espacio social, toda interacción social aparece como un escenario para mostrar el cuerpo, para mostrarse como personalidad. E incluso, para muchos, sobre todo adolescentes, el cuerpo es la única o privilegiada manera de mostrarse. Tal es la centralidad de lo corporal para muchos jóvenes, que incluso lo importante no es el cuerpo que uno tiene, sino el cuerpo que uno puede llegar a tener. Más que ser, lo importante es el parecer. El proyecto vital parece anclarse en ese cuerpo ideal que se espera construir. Y para ello las técnicas quirúrgicas, las dietas, las pastillas, las máquinas para hacer ejercicios se convierten en accesorios indispensables. Son el bálsamo mágico que promete la ilusión del reequilibrio narcisista: "No soy nadie si no soy be1la, para ser bella tengo que ser delgada, mientras más delgada más valorada y aceptada".

La fuerza de este paradigma de la esbeltez es enorme. Basta mencionar que mientras navegaba en internet, visitando algunas páginas sobre el tema de desórdenes alimenticios, se colaban constantemente una serie de páginas de publicidad anunciando pastillas, máquinas o artefactos que prometían bajar de peso, moldear el cuerpo, entre muchas otras ofertas, en otras palabras, la industria en torno a la delgadez atacaba el núcleo mismo de la resistencia ante la fetichización de la delgadez (las páginas que consultaba eran páginas de autoayuda, direcciones de clínicas o de instituciones que ofrecían psicoterapia).

La publicidad que comento nos ofrece un proyecto para vivir a partir de la gestión corporal, siguiendo el ideal de la esbeltez. Ya es parte del sentido común que esos ideales corporales tienen -por sedimentación y repeticiónuna gran capacidad para generar voluntad de imitación por parte de las jóvenes y adolescentes, quienes buscan modelos (que no sean los parentales) para construir su propio proyecto vital. Para resaltar la dificultad y sufrimiento que implica para las personas asumir ese ideal de esbeltez en sus propios cuerpos, NEDIC, un grupo de apoyo canadiense sobre desórdenes alimenticios nos propone -de manera lúdicacomparar las dimensiones corporales de las mujeres promedio en los países desarrollados, la que tendría una muñeca Barbie proyectada a dimensiones humanas y el típico maniquí de escaparate o vitrina. 
Tabla No 1

Pesos y medidas de la mujer promedio, la muñeca Barbie proyectada a escala humana y el maniquí de vitrina

\begin{tabular}{lccc}
\hline & Mujer promedio & Barbie & Maniquí de vitrina \\
\hline Estatura & $1,60 \mathrm{~m}$ & $1,80 \mathrm{~m}$ & $1,80 \mathrm{~m}$ \\
Peso & $65,9 \mathrm{Kg}$ & $45,9 \mathrm{Kg}$ & --- \\
Talla de vestido & $11-14$ & 4 & 6 \\
Busto & $90-93 \mathrm{~cm}$ & $98 \mathrm{~cm}$ & $85 \mathrm{~cm}$ \\
Cintura & $73-78 \mathrm{~cm}$ & $48 \mathrm{~cm}$ & $58 \mathrm{~cm}$ \\
Cadera & $100-105 \mathrm{~cm}$ & $83 \mathrm{~cm}$ & $85 \mathrm{~cm}$ \\
\hline
\end{tabular}

Fuente: http://www.anred.com/stats.html

Este ejemplo nos muestra que los medios presentan imágenes corporales difíciles de alcanzar, pero que se constituyen en el yo ideal del común de las personas: eso que todos quieren parecer.

Diferentes estudios muestran la importancia que tienen los cuerpos y sus dimensiones para las jóvenes. En la medida en que la pubertad y la adolescencia constituyen períodos de vulnerabilidad narcisista, la fetichización de la delgadez brindaría la ilusión de un reequilibrio. Lo decíamos hace un momento: "Sólo si soy delgada seré valorada".

A continuación se muestran algunos datos provenientes de estudios empíricos diversos:

- En una encuesta elaborada por la Universidad de Exeter (Bleichmar, 2000) en Inglaterra, sobre 37.500 jóvenes entre 12 y 15 años, se encontró que para el 58\% su apariencia física era su mayor preocupación en la vida. También el estudio mostraba que el 59\% de las chicas, entre 12 y 13 años, que presentaban una baja autoestima se encontraban "haciendo dieta".

- En un estudio que realizamos en la Universidad de Lima con la profesora Alicia Pinzás, entre estudiantes de 16 a 19 años, encontramos que el $85 \%$ de las jóvenes le atribuían a su apariencia corporal una significativa importancia. Mientras en los varones sucedía lo mismo en un $77 \%$. Ambas cifras muestran la gran importancia que cobra la apariencia física para los jóvenes y ya no sólo para las púberes.

Sin embargo, a pesar de que para varones y mujeres la apariencia es fundamental, encontramos diferencias respecto de las pedagogías para modelar el cuerpo según sexo.

Dietas y gimnasia parecen ser las especialidades femeninas, mientras el deporte es la masculina. Esto muestra que la presión social sobre las mujeres tiende a ser mucho mayor que la que encontramos en varones. Sin embargo, los varones más vulnerables a las dietas (y a la 
Tabla $\mathbf{N}^{\circ} 2$

Métodos para conservar la apariencia física según sexo

\begin{tabular}{lrr}
\hline & Mujeres & Hombres \\
\hline Sólo dieta & $15,1 \%$ & $0 \%$ \\
Sólo gimnasia & $8,4 \%$ & $2,6 \%$ \\
Dieta y gimnasia & $11,9 \%$ & $0 \%$ \\
Pastillas contra el apetito & $0,7 \%$ & $0 \%$ \\
Sólo deporte & $10,5 \%$ & $53,5 \%$ \\
Dieta y deporte & $6,3 \%$ & $0 \%$ \\
Deporte, gimnasia y dieta & $4,2 \%$ & $8,3 \%$ \\
Otros & $14,2 \%$ & $11,7 \%$ \\
Nada & $27,3 \%$ & $23,0 \%$ \\
No responde & $1,4 \%$ & $0,9 \%$ \\
TOTAL & 100,0 & 100,0 \\
\hline
\end{tabular}

Fuente: KOGAN, Liuba y Alicia PINZÁS. "Representaciones corporales en jóvenes de clase media". Plural, 6-7. Lima: Universidad de Lima, 1998.

anorexia o bulimia) parecen ser aquellos que feminizan su cuerpo, los homosexuales; o de lo contrario, deportistas que desean bajar de peso con una gran vehemencia para poder competir en categorías inferiores con mayor ventaja.

En general el cuerpo de las mujeres (y de un porcentaje minoritario de varones) parece convertirse en el locus privilegiado de la construcción de la personalidad. Sin embargo, en el caso de las mujeres es interesante plantear la encrucijada en la que se juega el drama de esta construcción de la corporalidad, junto con el drama de la construcción de la identidad del género. Nos referimos al hecho de exigirle a la mujer la masculinización del carácter (deben ser asertivas, fuertes, decididas, exitosas, etc.) pero a la vez imponerle una extrema feminización de la apariencia.

Lipovetsky (1999) escudriña a esta "tercera mujer", que debe ser mucho más que la superación de la mujer tradicional y la construcción de la mujer masculinizada. A la vez, deberíamos señalar que las adolescentes se ven forzadas a iniciar su vida sexual cada vez más precozmente, lo que las coloca en una situación de vulnerabilidad que se acentúa con el imperativo de ser cada vez más autónomas respecto a las referencias de protección y apego de la infancia. En resumidas cuentas, no sólo se le exige a la mujer una apariencia que lleve a la admiración, sino además autonomía.

En este panorama de una sociedad hedonista y somatizada, donde los problemas políticos y morales se exponen en la conducción de los cuerpos, quiero proponer que los cuerpos anoréxicos y bulímicos, como también los vigoréxicos que desarrollan los físicoculturistas, son cuerpos liminales (o extremos) de una sociedad que juega los signifi- 
cados culturales y de poder "tan cerca y tan lejos" en los cuerpos. En otras palabras, los cuerpos anoréxicos, bulímicos y vigoréxicos nos permiten hablar de los cuerpos en general, porque se trata de la expresión llevada a los síntomas extremos de nuestros tiempos; es decir, se trata de llevar a los extremos los ideales corporales socialmente aceptados, convirtiendo a esos cuerpos liminales en objeto de repulsión y simpatía. En inglés se los ha bautizado como freak (Garland, 1996).

Se trata, pues, de cuerpos excepcionales o anómalos, que nos permiten manejar nuestras ansiedades e incluso preguntarnos por la economía política de los cuerpos en nuestros tiempos.

Quisiera recalcar que con el advenimiento de la modernidad aparece una fascinación por los cuerpos liminales. Los cuerpos extraños, monstruosos o prodigiosos: el hombre más alto o más bajo, el hombre lobo (cubierto de bellos), la mujer con barba o la de la cintura más estrecha. Los cuerpos liminales generaban una narrativa de lo maravilloso y se los mostraba en espectáculos circenses para generar asombro y entretenimiento; mientras hoy la narrativa generada en torno a estos cuerpos es el discurso de la patología y del error.

Es indudable, pues, que nos hemos envuelto de un discurso medicalizado, que responde a lo que Foucault consideraba la "microfísica del poder" o cómo las instituciones se imponen a los cuerpos hasta volverlos dóciles. Las institu- ciones nos educan para controlar nuestra ubicación espacial, nuestros movimientos y nuestra relación con los objetos.

Propongo que, más allá de encontrar los afrontes terapéuticos adecuados para tratar el sufrimiento que causa tener/ser un cuerpo anoréxico, bulímico o vigoréxico, debemos ubicarnos también -los que no tenemos esos cuerpos liminales- frente a las preguntas que esos cuerpos nos plantean y sentirnos interpelados como sociedad (Hewitt, 1997): qué valores, qué ideales estamos generando y qué consecuencias acarrean.

A manera de conclusión, se puede afirmar que los cuerpos vigoréxicos de los físico-culturistas, como los cuerpos anoréxicos y bulímicos, representan los límites o extremos de una escala donde el eje central es el ideal corporal de las sociedades del capitalismo tardío.

En la columna central del siguiente cuadro graficamos el ethos de la sociedad occidental, que se vuelca hacia el cuerpo debido al enorme narcisismo y hedonismo que genera, por lo que se produce una fuerte preocupación por la alimentación y la producción social de la corporalidad; mientras en la primera columna podemos apreciar que quienes desarrollan cuerpos vigoréxicos buscan trascender a partir de una enorme musculatura. Sería el eje donde la escala corporal se agranda, a partir de la adopción de un régimen alimenticio orientado a eliminar grasa y ganar músculos. Este estado liminal nos plantea la para- 
Tabla $\mathbf{N}^{\circ} 3$

Cuerpos liminales

\begin{tabular}{lll}
\multicolumn{1}{c}{$\begin{array}{c}\text { Estado liminal: } \\
\text { vigorexia }\end{array}$} & \multicolumn{1}{c}{$\begin{array}{c}\text { Ideales, valores del } \\
\text { capitalismo tardío }\end{array}$} & \multicolumn{1}{c}{$\begin{array}{c}\text { Estado liminal: } \\
\text { anorexia, bulimia }\end{array}$} \\
\hline $\begin{array}{l}\text { Búsqueda de una muscularidad } \\
\text { trascendente que busca mos- } \\
\text { trarse públicamente }\end{array}$ & $\begin{array}{l}\text { Narcisismo, hedonismo, ego- } \\
\text { centrismo }\end{array}$ & $\begin{array}{l}\text { Búsqueda de una trascendencia } \\
\text { espiritual (purificación, as- } \\
\text { cetismo religioso) para la au- } \\
\text { toafirmación. }\end{array}$ \\
$\begin{array}{l}\text { Eliminar grasa para ganar mus- } \\
\text { culatura }\end{array}$ & La dieta o régimen alimenticio & $\begin{array}{l}\text { Adelgazar: autodefinición + au- } \\
\text { toaniquilamiento. }\end{array}$ \\
$\begin{array}{l}\text { Agrandar el cuerpo vía la mus- } \\
\text { cularidad e implantes }\end{array}$ & La escala corporal & $\begin{array}{l}\text { Disminuir el tamaño, dimensio- } \\
\text { nes y formas }\end{array}$ \\
$\begin{array}{l}\text { Cuestiona la construcción de la } \\
\text { feminidad al masculinizar o } \\
\text { empoderar a la mujer, generan- } \\
\text { do indiferenciación femenino- } \\
\text { masculino. }\end{array}$ & Sistema sexo-género-cuerpo. & $\begin{array}{l}\text { Cuestiona la construcción de la } \\
\text { sexualidad generando la in- } \\
\text { fantilización o androginia en los } \\
\text { cuerpos: genera indiferenciación } \\
\text { femenino-masculino. }\end{array}$ \\
\hline
\end{tabular}

Fuente: elaboración propia

doja de la diferenciación femenino-masculino a partir de la construcción corporal, ya que las mujeres vigoréxicas construyen cuerpos masculinizados.

Al otro extremo -en la tercera columna- tenemos los cuerpos anoréxicos que plantean el ideal de una trascendencia espiritual y autoafirmación anclados en un ascetismo cuasi religioso y purificador a partir de una dieta que busca el adelgazamiento extremo, produciendo la reducción de las dimensiones corporales, que en casos extremos conlleva el autoaniquilamiento. En estos casos encontramos la produc- ción de cuerpos andróginos o indiferenciados genéricamente.

En síntesis, cuando hablamos de cuerpos anoréxicos, bulímicos y vigoréxicos también estamos hablando de los otros cuerpos y de las otras formas de alimentación, como de los ideales y valores de las sociedades del capitalismo tardío.

Planteamos, por lo tanto, desplegar una mirada comprensiva frente a quienes encarnan en sus cuerpos -en los extremos de la escala señalada- el sufrimiento, el dolor y la rabia que son, en realidad, los síntomas más extremos de los ideales que todos compartimos. 


\section{REFERENCIAS}

Asociación Germinal (1996). Identidad prohibida. Lima: Asociación Germinal.

Bleichmar, E.D. (2000). Anorexia/bulimia. Un intento de ordenamiento desde el enfoque modular-transformacional. Revista de Psicoanálisis, 4.

Dongju, Y. (1998). Cultura publicitaria y políticas del cuerpo femenino. La mujer coreana entre el confucianismo y el capitalismo. Comunicación y Sociedad, 34.

Duby, G. y Perrot, M. (1993). La historia de las mujeres. El siglo XIX. Cuerpo, trabajo y modernidad. Madrid: Taurus Ediciones.

Garland, R. (1996). Freakery. Cultural spectacles of the extraordinary body. New York: New York University Press.

Hewitt, K. (1997). Mutilating the body. Identity in blood and ink. Bowling Green: Bowling Green State University Popular Press.

Lipovetsky, G. (1999). La tercera mujer. Barcelona: Anagrama.

Lipovetsky, G. (1990). El imperio de lo efimero. La moda y su destino en las sociedades modernas. Barcelona: Anagrama.

Lock, M. (1993). Cultivating the body: anthropology and epistemologies of bodily practice and knowledge. Annual Revier Anthropology, 22, 133-135.

Messer, E. (1984). Anthropological perspectives on diet. Annual Review Anthropology, 13, 205-249.

Scheper-Hughes, N. (1997). La muerte sin llanto. Barcelona: Ariel.
Taylor, Ch. (1994). La ética de la autenticidad. Barcelona: Paidós.

Turner, B. (1996). The body \& Society. Explorations in social theory. Londres: Sage Publications.

Zavala, L. El vestido en la vida cotidiana urbana. Topodrilo, 33, http://www.iztapalapa.uam.mx/iztapalapa.www/topodrilo/ 